\title{
USER PREFERENCES IN IMAGE MAP USING
}

\author{
A. Vondráková *, V. Vozenilek \\ Department of Geoinformatics, Faculty of Science, Palacký University Olomouc, 17. listopadu 50, 77146 Olomouc, Czech Republic \\ alena.vondrakova@upol.cz, vit.vozenilek@upol.cz
}

Commission SpS4 - ICA

KEY WORDS: Image Map, User Issues, User Preferences

\begin{abstract}
:
In the process of map making, the attention is given to the resulting image map (to be accurate, readable, and suit the primary purpose) and its user aspects. Current cartography understands the user issues as all matters relating to user perception, map use and also user preferences. Most commercial cartographic production is strongly connected to economic circumstances. Companies are discovering user's interests and market demands. However, is it sufficient to focus just on the user's preferences? Recent research on user aspects at Palacký University Olomouc addresses a much wider scope of user aspects. The user's preferences are very often distorting - the users think that the particular image map is kind, beautiful, and useful and they wants to buy it (or use it - it depends on the form of the map production). But when the same user gets the task to use practically this particular map (such as finding the shortest way), so the user concludes that initially preferred map is useless, and uses a map, that was worse evaluated according to his preferences. It is, therefore, necessary to evaluate not only the correctness of image maps and their aesthetics but also to assess the user perception and other user issues. For the accomplishment of such testing, eye-tracking technology is a useful tool. The research analysed how users read image maps, or if they prefer image maps over traditional maps. The eye tracking experiment on the comparison of the conventional and image map reading was conducted. The map readers were asked to solve few simple tasks with either conventional or image map. The readers' choice of the map to solve the task was one of investigated aspect of user preferences. Results demonstrate that the user preferences and user needs are often quite different issues. The research outcomes show that it is crucial to implement map user testing into the cartographic production process.
\end{abstract}

\section{INTRODUCTION}

Maps are a natural part of the modern world. The general public use them in everyday life; experts use them as a way of presenting particular issues or outcomes of research studies; teachers use them as a means of understanding the world; politics use them as an argument for the realization of relevant interests. Maps importance is indisputable.

The suitability of selected cartographic methods and their applications significantly affect the user's ability to gain quick access to the correct information from a map. Therefore, in the process of map making, it is crucial to pay attention not only to the resulting map but also to the user aspects. This is equally important for image maps, which are a relatively new method of cartography.

The quantification and evaluation of different factors on the information perception from a map by various groups of users are the main tasks in many kinds of research. Mostly there are used traditional thematic maps with some topographical base, but in recent years come to the fore also image maps.

The research focused on user aspects, conducted at Palacký University Olomouc, has shown that user preferences are not same as user needs. Therefore, it is important not only to ask map users for their preferences on the use of image maps, but it is also important to perform user testing. User testing, evaluation of user requirements, user needs and user preferences are closely related to the research area of map user issues.

Image maps (orthoimage maps) have become very popular and frequently produced cartographical outputs in geosciences during recent years. This paper deals with the new approach to user testing of user preferences in image map using eye-tracking technology (Popelka, Vozenilek 2013).

\section{USER ISSUES IN CARTOGRAPHY}

\subsection{User issues}

The user issues in cartography are determined by the users of cartographic works and represent the most significant influence in the process of map creation (Vondráková, 2013). It is needed to take particular attention to the user requirements and preferences. These issues should be the determining factor in creating the concept of any cartographic work, including image maps.

The paper focuses on two aspects of the user issues. The first part consists of studying user preferences vs. user needs. The second part concentrates on the comprehensive testing of image maps, which includes both user preferences and needs.

\subsection{Map information perception}

According to Kraak and Ormeling (2003) maps help their users to understand better geospatial relationships and users can get and quantify relations and information. To ensure that user is provided with the correct information and that the right information is also gaining by the user, it is needed to have the relevant data and to use a suitable method of cartographic visualization. Ways in which users read maps are crucial determinants of the effectiveness of such maps.

Selection of the appropriate methods of cartographic visualization and appropriate parameters of each method is the main task for each cartographer. To achieve this goal, it is necessary to perform user testing through the use of various cartographic tasks (Vondráková, Popelka 2014). The research consisted of user testing can reveal incompatibility between user preferences and needs. 


\subsection{Eye-tracking in cartography}

The map user has to be able to interpret the content of the map correctly and accurately. The technology of eye-tracking allows analysing not only the speed and method of reading maps but also recording the correctness or precision of the user response (Vondrakova, Popelka, 2014).

Eye-tracking technology is one of the methods of usability studies and is considered as an objective because the opinion of respondents does not influence it. Based on the technological development and the enhancement of eye-tracking technology accessibility, this method became a part of cartographic research last years. The modern eye-trackers use non-invasive contactless measurements in the visible areas of the eye (Brychtova, Popelka, Vozenilek 2012). The reflected light is recorded camera. From the analysis of the changes of corneal reflection, the point of regard is calculated. Data from the eye-tracking experiment contains a large number of timestamp and measured values. The most important are coordinates of the point of regard, the radius of the pupil, the eye position, etc.

The research was performed in the eye-tracking laboratory (Fig. 1) equipped by remote SMI RED 250 eye-tracker with 120 $\mathrm{Hz}$ sampling rate, $0.4^{\circ}$ accuracy, and $0.03^{\circ}$ spatial resolution.

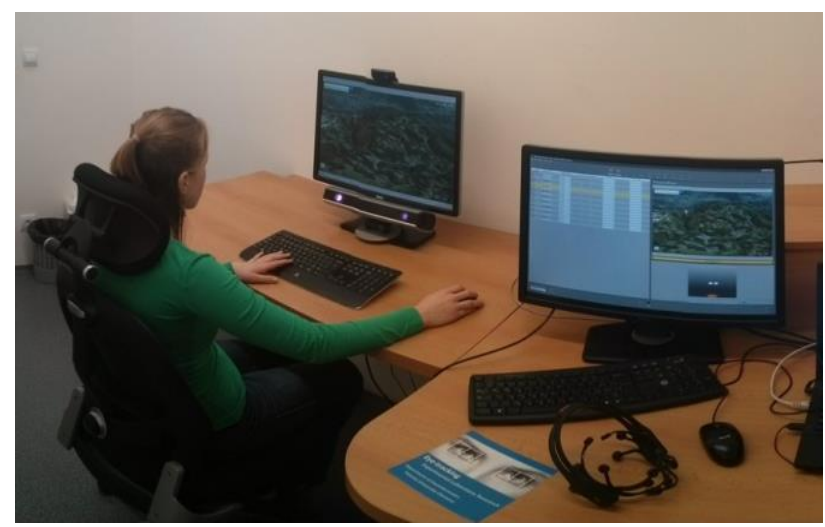

Figure 1. Controlled eye-tracking laboratory.

The eye-tracking system is accompanied by the 21.5" LED monitor Dell P2213. Data capturing, experiment design, gaze event detection, and data filtering were processed by SMI Experiment Suite $360^{\circ}$ and Ogama 5.0 software. Eye-events fixation, saccades, and blinks were identified by dispersion threshold algorithm (ID-T) with dispersion threshold $50 \mathrm{px}$ and duration threshold $80 \mathrm{~ms}$.

\section{USER PREFERENCES VS. USER NEEDS}

There are many kinds of research discovering user's interests and their preferences. However, is it sufficient to focus just on the user's preferences? Research focused primary on the evaluation of promotion city plans of selected cities in the Czech Republic has shown that it is not. User testing and the assessment were performed by Selníková (2016).

\subsection{User preferences}

The research to determine the general preference of users for promotional maps, as well as to determine the preference of the map style maps and map symbols, was performed via the online questionnaire. The online questionnaire survey was chosen because it is not limited by space and time as laboratory experiments (eye-tracking experiments).
In total, 353 respondents completed the questionnaire. The survey was conducted by 248 (70.3\%) women and $105(29.7 \%)$ men. Most respondents were in the age category of 16-25 (271 responses, $76.8 \%$ ). The questionnaire was distributed via social networks and mail lists.

For the evaluation of general preferences, respondents were asked about format and map content. The most popular are the A4 size (42.8\%), followed by folded map (36.8\%). Respondents welcome information about public transportation (95.6\%) and information on tourist interests $(89.9 \%)$.

More important for the presented research, was a part focused on the preferences of map style. Respondents were asked to evaluate the aesthetics and usability of selected maps. The evaluation was carried out on a scale $1-5$ (1 as a minimum; 5 as a maximum). The highest average ratings reached the map of Hradec Králové (aesthetics 3.5 and 3.7 usability - Fig. 2), second place maps of Brno and Jihlava, followed by the map of Olomouc. The worst rating had the map of Ostrava (2.2 aesthetics and 2.2 usability). Respondents consider maps of České Budějovice and Plzeň as more aesthetic than practical. Map of Ceske Budejovice use only a 3D view of buildings, but the ones in some cases reduce the legibility of the map. In the map of Plzeň, illustrative symbol characters are used, which can cause an aesthetic impression.

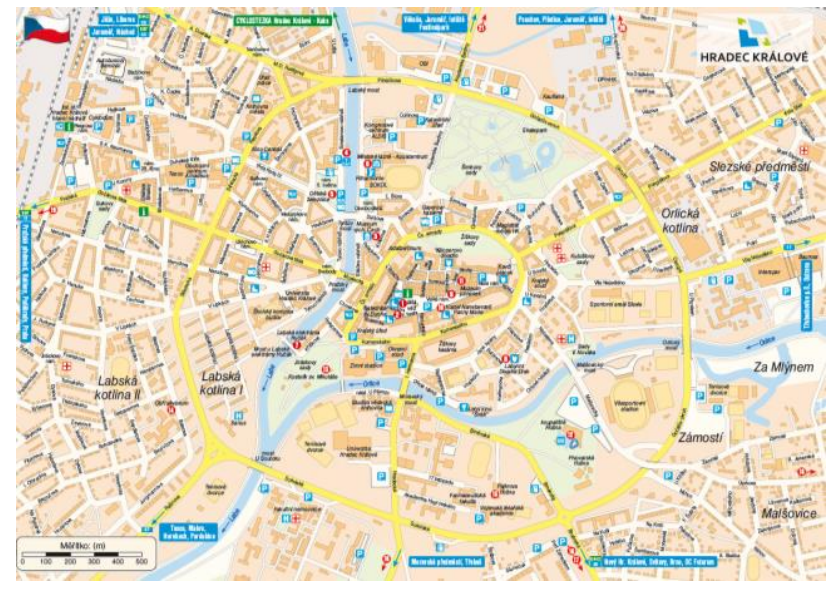

Figure 2. Example of a map preferred by users in aesthetics (map of Hradec Králové city).

Results of the online questionnaire can be interpreted that users prefer also painted maps with 3D views because of its aesthetics.

\subsection{User needs}

In the eye-tracking experiment, respondents were asked to find information centre of the city in each map and also they were asked to get the shortest way from point A to point B. Analysis and processing of the data were performed in the SMI BeGaze software; statistical analyses were performed in the RStudio software and some visualization were created using V-Analytics and ArcGIS for Desktop software.

Fig. 3 present the time duration (ms) needed to find the correct answer (finding the information centre). The highest timeduration index was performed on the map of Pardubice city (Fig. 4). The largest number of incorrect pathfinding was again at the map of Pardubice city. Only 15 respondents (44\%) had found the right answer. Upon closer examination of the eye movements of individual entities, we can say that the main problem was because the text labels are too small on the map. 


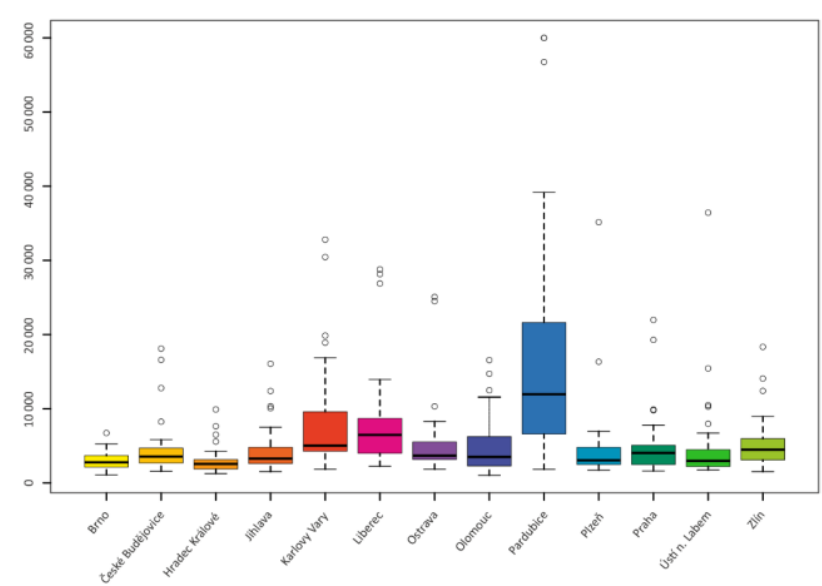

Figure 3. Boxplot - time duration of finding the answer to the task during the eye-tracking experiment.

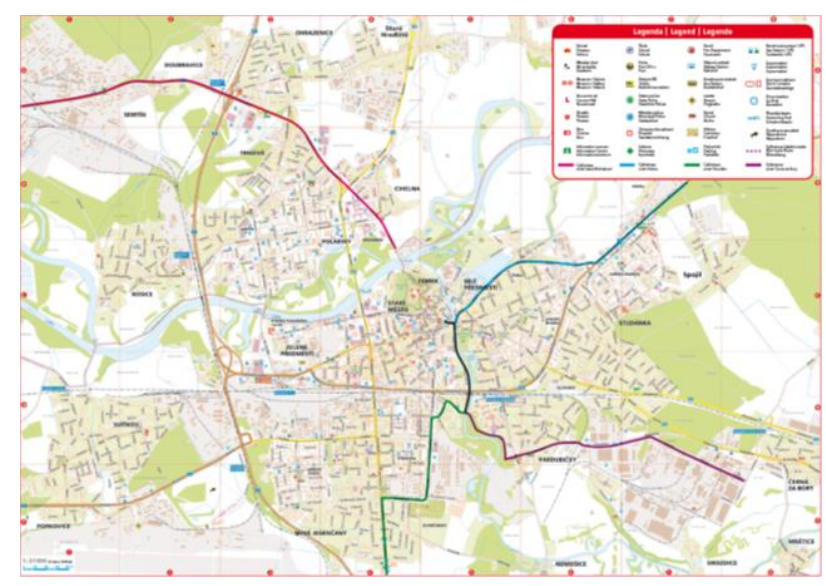

Figure 4. Map of Pardubice city (eye-tracking experiment).

Although the map of Pardubice city (Fig. 4) was released as the worst during the user testing, according to user preferences this map should be good - there are used the preferred symbols, colours and map style.

User preferences are based on various issues - and most of them are subjective. During the user testing respondents had to find a right answer to simple tasks - and that time they found the size of the labels is too small, making the map confusing and very difficult to work with. According to user preferences would map be acceptable, according to user needs are not.

\subsection{Research conclusion}

In fact, user's preferences are very often distorting - the users think that the particular image map is kind, beautiful, and useful. But when the same user gets the task to use practically this particular map (such as finding the shortest way), so the user concludes that initially preferred map is useless, and uses a map, that was worse evaluated according to his preferences. It is, therefore, necessary to evaluate not only the correctness of image maps and their aesthetics but also to assess the user perception and other user issues. For the accomplishment of such testing, eye-tracking technology is a useful tool. Presented results are simplified for the purposes of an illustrative comparison between user preferences and user needs.

\section{PREFERENCES IN USING IMAGE MAPS}

The research task was to identify user's preferences in using conventional (topographic) maps or image maps. Experiment implementation also included the evaluation of differences in reading image maps and conventional maps. User testing and the assessment were performed by Fryčák (2016).

\subsection{Conventional maps vs. image maps}

Conventional maps, as known for centuries, is a representation, usually on a plane surface, of all or part of the earth showing a group of features in traditional visual ways based on point, linear and areal symbols. Maps provide modelling of reality through its abstraction and simplification that people have learned to routinely perceive and understand them (Svobodova, Vozenilek 2010).

On contrary image map involves into its compilation a novel source of information - a digital image captured by remote devices. The satellite and aerial imageries have become very popular and frequently used for analytical and visualization purposes in geosciences during recent years (Horak et al., 2011; Kudelka et al., 2012).

Belka and Vozenilek (2014) define an image map as a special map portraying geographic space in a particular cartographical projection and map scale, where its content consists of two basic components - image and symbol components. Image component is represented by the remote sensing image(s) while symbol component is represented by cartographical symbols. An image map has to have three essential attributes: cartographical projection, map scale and symbol component by means of map language.

\subsection{User preferences}

The experiment was aimed at finding user preferences in using conventional or image maps. Each experiment stimulus consisted of two parts - a conventional map and image map. Both maps presented the same area at the same scale; both maps had the same resolution and size. To prevent possible directionality in reading there were created the equivalent stimulus to display map tiles opposite lateral localization. This approach prevented the preferences based on the map position.

Testing focused on three user tasks:

- the positioning of individual objects,

- distinguishing vegetation,

- $\quad$ searching for transport paths and other tasks related to transportation.

Each task consists of the research question, the null hypothesis, experiment questions and registered eye-tracking metric. 40 respondents were involved in testing. Each respondent solved 20 tasks with twenty stimuli (pairs of conventional and image maps - Fig. 5). Each task had a time limit of 45 seconds. The testing method based on "within-subject design" was used. It ensured that each respondent was exposed to the whole testing whole. 


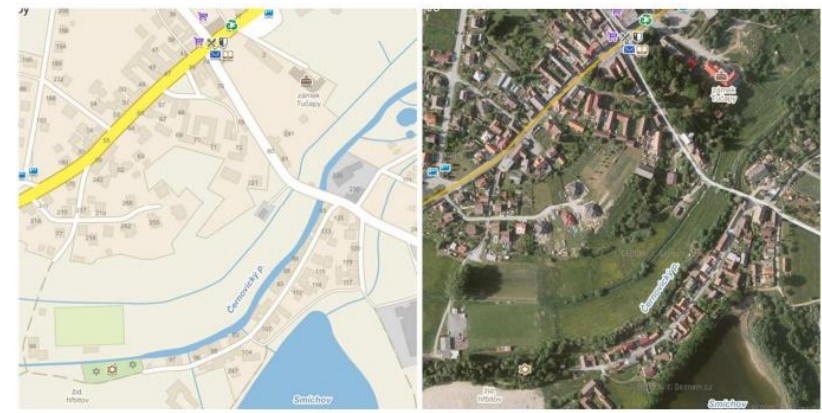

Figure 5. The example of experimental stimuli - conventional map (left) and image map (right).

Four eye-tracking metrics were applied: dwell time, fixation count, the number of responses and the accuracy of answers. The measured values were processed statistically and visualized by box plots.

Box plot (Fig. 6) shows less fixation count on the image maps (left) than on the conventional maps (right). Box plot in Fig. 7 displays how long respondents used the image map and conventional map to solve the experiment task.

Fixation Count

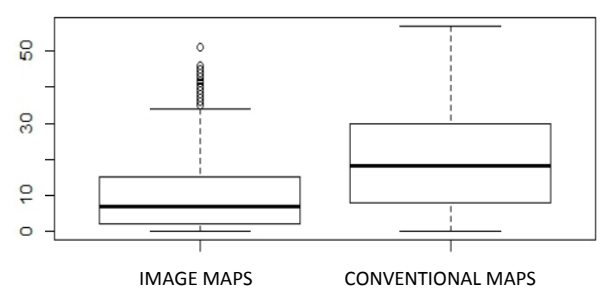

Figure 6. Fixation count boxplot - image maps (left) and conventional maps (right).

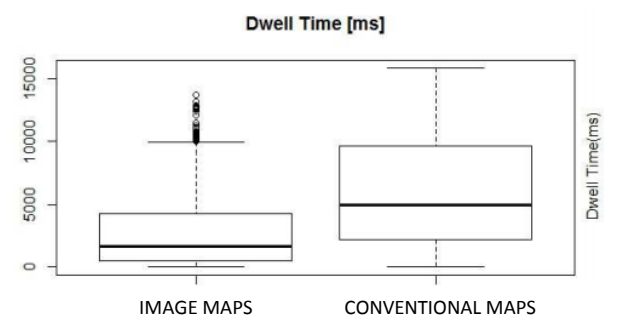

Figure 7. Dwell time boxplot - image maps (left) and conventional maps (right).

Users aspect of differences between conventional and image maps were investigated by tracking of respondent's eye movement during solving tasks. The experiment involves, for example, following tasks:

- $\quad$ positioning of individual objects
$\circ \quad$ Where is the theatre? Click there!
$\circ \quad$ Is the cemetery inside the village?
○ Click on the largest waterbody.

- distinguishing vegetation

- Click on the Bezručův park park.

- Is vegetation greater than bulit-up area?

○ Click on the largest park.

$\circ$ What is the name of the park east of the language school?
- $\quad$ searching for transport paths and other tasks related to transportation

$\circ \quad$ Click on all bridges.

- Sign the shortest way from cinema Portyč to the Frán̆a Šrámek theatre.

- How many streets cross the main avenue?

The measured values of eye-tracking metrics were analysed using the SMI BeGaze and Microsoft Excel software.

\subsection{Research conclusion}

The research analysed user's preferences in using image maps (next to conventional maps). All eye-tracking metrics reached higher values for conventional maps for all three tasks (positioning, vegetation, and transportation). There was not confirmed that users would prefer image maps over conventional maps although at individual questioning respondents' answers differed. The eye-tracking experiment on the comparison of the conventional and image map reading was conducted and there were evaluated user's preferences in using different maps to solve the task.

\section{CONCLUSION}

Results of particular research focused on the evaluation of promotional city plans (maps) demonstrate that the user preferences and user needs are often quite different issues. It is necessary to evaluate not only the correctness of maps and their aesthetics but also to assess the user perception and interpretation of perceived information. For the accomplishment of such testing, eye-tracking technology is a useful tool.

The research focused on the user preferences in using image or conventional maps demonstrate that there is no significant preference of using image or conventional map during the task processing.

The research outcomes show that it is crucial to implement map user testing into the cartographic production process. User issues are an important part of map-making and it is not enough to determine user preferences during map compilation, as these preferences may be different from real user needs.

\section{ACKNOWLEDGEMENTS}

The authors acknowledge the support by the Operational Program Education for Competitiveness, European Social Fund, project CZ.1.07/2.3.00/20.0170 of the Ministry of Education, Youth and Sports of the Czech Republic, and project IGA_PrF_2014007 of the Palacký University, Olomouc.

\section{REFERENCES}

Belka, L., Vozenilek, V. Prototypes of orthoimage maps as tools for geophysical application. Pure and Applied Geophysics 171.6 (2014): 1047-1059. DOI 10.1007/s00024013-0665-y

Brychtova, A., Popelka, S., Vozenilek, V. The Analysis of Eye Movement as a Tool for Evaluation of Maps and Graphical Outputs from GIS. Proceedings of $19^{\text {th }}$ International Conference on Geography and Geoinformatics: Challenge for Practise and Education, Brno, 2011, 154-162 pp. 
Horak, Z., Kudelka, M., Snasel, V., Vozenilek, V. Orthophoto map feature extraction based on neural networks. CEUR Workshop Proceedings, Vol. 706, 2011. 216-225 pp.

Fryčák, A. Differences in Reading Orthoimage Maps and Conventional Maps [Odlišnosti čtení ortofotomap a konvenčních map]. Bachelor thesis. Department of Geoinformatics, Palacký University Olomouc, 2016. Supervisor Vít Voženílek.

Kraak, M. J., Ormeling, F. Cartography: Visualization of Geospatial Data. Second edition, Pearson Education Limited, Essex, 2003.

Kudelka, M., Horak, Z., Vozenilek, V., Snasel, V. Orthophoto Feature Extraction and Clustering. Neural Network World, Vol. 22, No. 2, 2012, 103-121 pp.

Popelka, S., Vozenilek, V. Specifying of Requirements for Spatio-Temporal Data in Map by Eye-Tracking and SpaceTime-Cube. International Conference on Graphic and Image Processing (ICGIP 2012), Proceedings of SPIE, Vol. 8768, Article Number: 87684N, 2013.

Selníková, N. Evaluation of City Promotional Maps by Eyetracking Technology [Hodnocení propagačních trhacích map měst metodou eye-tracking]. Bachelor thesis. Department of Geoinformatics, Palacký University Olomouc, 2016. Supervisor Alena Vondráková.

Svobodova, J., Vozenilek, V. Relief for Models of Natural Phenomena. In: Anděl, J., Bičík, I., Dostál, P.,Shasneshin, S. (eds.): Landscape Modelling: Geographical Space, Transformation and Future Scenarios. Dordrecht, Springer, 2010. 183-196 pp.

Vondrakova, A. Non-technological aspects of map production. $13^{\text {th }}$ GeoConference on Informatics, Geoinformatics and Remote Sensing, SGEM2013 Conference Proceedings, ISBN 978-954-91818-9-0, 2013, Vol. 1, 813-820 pp., DOI: 10.5593/SGEM2013/BB2.V1/S11.026.SGEM

Vondrakova, A., Popelka, S. The Use of Eye-Tracking for the Evaluation of Various Cartographic Tasks. 14 ${ }^{\text {th }}$ SGEM GeoConference on Informatics, Geoinformatics and Remote Sensing3.SGEM2014 Conference Proceedings, ISBN 978-6197105-12-4, June 19-25, 2014, Vol. 3 (2014): 981-988 pp., DOI: 10.5593/SGEM2014/B23/S11.124

Revised April 2016 